\title{
Pedro de la Torre y los retablos baldaquino de la Virgen del Sagrario de Toledo y de los Ojos Grandes de Lugo
}

\author{
AdOLFO de ABEL VILELA
}

La introducción en Galicia del retablo-baldaquino, difundido por la escuela madrileña del siglo XVII, tendrá lugar a través de una traza hecha por su creador Pedro de la Torre para la Virgen del Sagrario de la catedral de Toledo. Esta obra de la catedral de Lugo, hoy desaparecida, se hará, con algunas modificaciones, por el entallador y arquitecto castellano Francisco González, destinada a albergar la imagen de la Virgen de los Ojos Grandes.

Terminado en 1656, el retablo-baldaquino lucense se anticipa ocho años al toledano, concluido en 1674, lo cual supone una curiosa novedad. Es probable que después de ver este prototipo, su divulgación en otros lugares próximos a Villafranca del Bierzo y Asturias la efectuase su ejecutor, artífice que, al parecer, gozaba de cierta fama y prestigio en aquellas tierras en las que desarrolló su trabajo.

Pero esta obra, que en su estructura básica no representa ninguna novedad por repetir el tema del baldaquino ahuecado, de larga tradición en la orfebrería española ', influiría también en el diseño del altar de San Isidro de Madrid, de Herrera Barnuevo, según Wethey ", y en los túmulos para las honras de diversos reyes, algunos diseñados por Pedro de la Torre.

La estructura no es exactamente lo que conocemos por baldaquín o baldaquino, como se sabe voz de origen italiano que proviene de Baldac, nombre medieval de Bagdad, de donde procedia una tela con esta denominación utilizada para los doseles o palios. Este elemento también se

Tovar Martin, Virginia. El arquitecto ensamblador Pedro de la Torre. Archivo Español de Arte. Madrid, 1973. pág. 292.

WEJHEY, H. Decorative Projects of Sebastián de Herrera Barnuevo. Burlington Magazine, xcVIII, núm. 635, 1956. págs. 41-46. 
acostumbraba a designar como umbraculum. Su origen es profano, inventado para ornamento de los solios de los príncipes de donde lo tomó la Iglesia para denotar la preeminencia y la autoridad de quien lo usaba.

El baldaquino que Bernini diseñó y ejecutó para la basílica de San Pedro de Roma, fue una composición ieliz, que sirvió de inspiración a multitud de artistas en toda Europa, los cuales reinterpretaron esta estructura, ya como un todo, o simplemente como una parte. Esto se puede comprobar en la similitud de algunos retablos del período barroco, y en tabernáculos ejecutados en el momento de depuración y simplificación neoclasicista, que desembocará en un neobarroco romano ${ }^{3}$.

A esta influencia tampoco fue ajeno Pedro de la Torre que sintetizó en esta traza, aunque, como veremos, sin despegarse de la tradición del baldaquino ahuecado o gloria que rodeaba a la patrona de Toledo, conocida popularmente como Nuestra Señora del Sagrario, por estar colocada a la entrada del relicario, depósito de las muchas y preciosas reliquias que siempre hubo en esta santa iglesia, a la cual se da justamente el nombre de Sagrario 4 .

Teniendo en cuenta la mala disposición que tenía el nicho que la albergaba en el antiguo Sagrario, el cardenal don Gaspar de Quiroga (15771594), decide ampliar varias dependencias de la catedral. La nueva construcción comprenderá, además de lo que será la capilla de esta denominación, el relicario, sacristía, patio y casa del tesorero.

Los planos o trazas fueron encargados a Nicolás de Vergara, El Mozo, que dirigió las obras hasta su muerte ocurrida en 1606. Iniciadas en 1594, tuvieron varias fases, tanto en lo que se refiere a la ejecución material como a la dirección técnica, siendo su gran impulsor don Bernardo de Sandoval y Rojas (1599-1618).

De 1606 a 1621, las continuó el arquitecto toledano Juan Bautista Monegro, sucediéndole a su muerte el hijo de El Greco, Juan Manuel Theotocopuli ${ }^{5}$,que se ocupó de ellas hasta su muerte acaecida en 1631. Las prosiguió Lorenzo de Salazar, que fallece en 1641.

Después de un paréntesis de inactividad, intervienen en los trabajos Lázaro de Goiti, Pedro de la Torre y el Hermano Bautista. En 1663 se ter-

Sobre este asunto ver: ABEL VILELA, ADOtFo. El tabernáculo de la catedral de Lugo, un ejemplo de neobarroco romano. Espacio. Tiempo y Forma. Serie vir. Historia del Arte. Tomo v. 1992. págs. 315-318.

Moreno Nieto, Luis. Guía de la Iglesia en Toledo. Toledo, 1975. pág. 135.

Chueca Goitia, Fernando. Catedrales de España. La Catedral de Toledo. León, 1984. pág. 134. 
mina la obra de cantería, encargándose el revestimiento del Ochavo, a! marmolista Bartolomé Zumbigo, que trabaja hasta 1671, aunque las obras no se pueden dar por terminadas hasta $1674^{\circ}$.

\section{EL TRONO Y EL CARRO PROCESIONAL}

Antes de la modificación de la capilla, la Virgen del Sagrario estaba sobre el Ochavo o Relicario, protegido por una verja de bronce para poder verlo, visión que no impedía la mesa del altar. Esta se encontraba separada y sólo tenía el tablero y la peana de sustentación. Confeccionada en mármol de Estremoz, llevaba cuadros embutidos de otros jaspes, ostentando en el frente un óvalo con una cruz patriarcal en su interior.

Las fiestas de la traslación y colocación de la imagen en la nueva capilla, fueron brillantísimas, como correspondia a todas las que, por diversos motivos, se celebran en la época. Duraron catorce dias, del 20 de octubre al 4 de noviembre de 1616, contando con la presencia, no sólo de los reyes, sino también de varios miembros de la familia real y de la nobleza. Hubo novenario, con nueve sermones distintos, certamen poético, procesión, toros, y suntuosas decoraciones que constituyen un ejemplo notable de arquitectura efímera.

Por las informaciones que nos ofrece Pedro de Herrera, futuro obispo de $T u^{2}{ }^{2}$, se hizo un nuevo carro procesional adaptado técnicamente, no sólo a las desigualdades que presentaba el pavimento de las calles, sino también a sus curvas y topografía, ingenio que fue diseñado por el arquitecto Juan Bautista Monegro.

El carro tenía cuatro ruedas pequeñas, las dos primeras con juego para tomar las curvas, sobre el que descansaba el trono. Este era de dos cuerpos, el inferior de 5 pies de alto y el superior de 1 vara. Se componía de una plataforma y tres gradas, cuyas formas facilitaban la transición paulatina del cuadrilátero al cilindro: la primera cuadrada, la segunda ochavada y la tercera cilindrica. Todo el conjunto tenia una altura de 2 varas y 2 tercias.

En la parte inferior del segundo cuerpo se ocultaba un mecanismo, nuevo ingenio de Juan Bautista Monnegro, pero en extremo seguro y bien

Pita Andrade, Jose Manuel y Alvarez Lofera, Jose. La arquitectura española del s. xvil. Summa Artis. Vol. XXVI. Cuarta edición. Madrid, 1988. págs. 463-464.

Herrera, Pedro de. Descripción de la capilla de Nuestra Señora del Sagrario que erigió en la Santa Iglesia de Toledo el Ilmo. Sr. carcenal D. Bernardo de Sandoval y Rojas... y relación de la antiguedad de la santa imagen con las fiestas de su traslación y solemnidad. Madrid, 1617. 
imaginado ${ }^{8}$, que permitía cierto movimiento para adaptarse a la pendiente de las calles de Toledo. Cuando subía una cuesta, bajaba lo necesario por la parte anterior con el fin de que la imagen, en su trono y pedestal, fuese siempre a un peso, y por tanto horizontalmente. Cuando descendía, el movimiento era contrario. Se hacia mediante una rueda de hierro hecha a puntos, regida por dos hombres que iban dentro, haciéndolo con tanto sosiego que no se percibía desde fuera.

La tradición de la orfebreria toledana se dejaba ver en el suntuoso conjunto. Las gradas estaban recubiertas con chapas de plata, con recuadros y florones bruñidos, todo labor maravillosa. Sobre la superior asentaba un circulo, formado de ocho cabezas de serafines, que iban encadenándose con las alas, en que descubrió el arte lo misterioso del último secreto suyo. La grada inferior iba poblada de doce imágenes de los apóstoles doradas, talla entera y vara en alto; las demás, enriquecidas de ramilleteros de flores naturales, $y$ algunas compuestas, y muchos pebeteros exhalando en humo regalados aromas; unos y otros, vasos todos, ángeles, imágenes, de plata ${ }^{3}$.

Desde la tabla o plano del segundo cuerpo, en la altura que podía levantarse, se cubria todo con cuatro paños de cortina blanca, brocado de lazos y florones de lo más rico, guarnecidas en los ángulos de alamares, flor y lazo de oro, con dos órdenes de flecos y franjas. En la parte anterior, llevaba dos enrejados, también de oro, para dar luz a cinco hombres que arrastraban y gobernaban el carro procesional. Con la misma tela se cubría el primer cuerpo hasta el suelo. En total se utilizaban 36 varas de tela.

La dirección o guia del carro procesional la marcaban dos prebendados tirando de gruesas cuerdas, rematadas en borlas de seda blanca, situadas en las esquinas anteriores del carro, indicando con ellas el movimiento que habian de hacer las personas que iban dentro.

En los ángulos del cuerpo bajo, llevaba cuatro cañones de hierro encubiertos, para sostener cuatro varas gruesas, doradas, de 14 pies de alto, sobre las que se armaba un toldo o pabellón, de encerado blanco, muy albo por fuera y raso del mismo color por dentro, decentemente obrado y guarnecido: túvose de prevención para la lluvia que se temía".

Ibidem. Fol. $82 \mathrm{v}$.

Ibidem. Fols. $82 v-83$.

Ibidem. Fol. $83 \mathrm{v}$. 
Por los datos que nos ofrece Herrera y muy especialmente por el grabado que ilustra su Descripción, el trono al que estaba atornillada la imagen, era, al igual que el actual, de plata bruñida y de exquisita labor.

Consistia en un arco de gloria, organizado en dos partes: la base y el arco.

La base o peana, sobre la que descansaba la imagen, presentaba una peculiaridad, como ya anticipamos. Estaba rodeada por ocho cabezas de serafines unidos por las alas. De esta forma la virgen adquiere un aspecto aéreo, recurso que también se va a utilizar en 1655 en la de la virgen de los Ojos Grandes de la catedral de Lugo, y que aún hoy conserva. La utilización de este recurso está relacionado con la celebración de su festividad en el día de la Asunción.

Todo el arco, guarniciones y figuras eran de plata blanca, bruñida y de talla entera o de bulto redondo, ornamento riquísimo de mucho decoro $y$ artificio ${ }^{11}$.

El testimonio gráfico que figura en la Descripción, nos ahorra mayor explicación. Se trata de un grabado en cuyo pie figura el siguiente texto:

P. P. F. 1617. En Madrid en casa de Luis Sánchez. 1617.

Representa una cartela, ovalada, que contiene el título del libro. En la parte inferior un escudo con corona marquesal, sostenido por las garras cie dos leones rampantes, rodeado por un aro oval vegetal.

En la parte superior, un resplandor, para vestir de sol la imagen de la virgen, como en la mujer apocalíptica, indicándose que es el verdadero retrato de Nuestra Señora del Sagrario, y a ambos lados lleva una vara de lirio.

Sobre el cerco de serafines de los dos lados, se levantaba, formando claro, un arco de trono, o baldaquino ahuecado, trabajado por el exterior con rayos, estrellas y espejos pequeños. Desde el nacimiento o arranque del trono, se arrimaban dos ángeles, de más de 1 vara de alto (unos 0,80 metros), con las manos puestas en actitud de orar, mirando hacia fuera, como los dos querubines del Sancta Sanctorum:

\section{Et facies eorum erant versus ad exteriorem domum ${ }^{\prime \prime}$}

Sobre estos, otros dos contrapuestos, también con las manos juntas. El resto del arco estaba formado de rayos, estrellas y espejos, rematando 


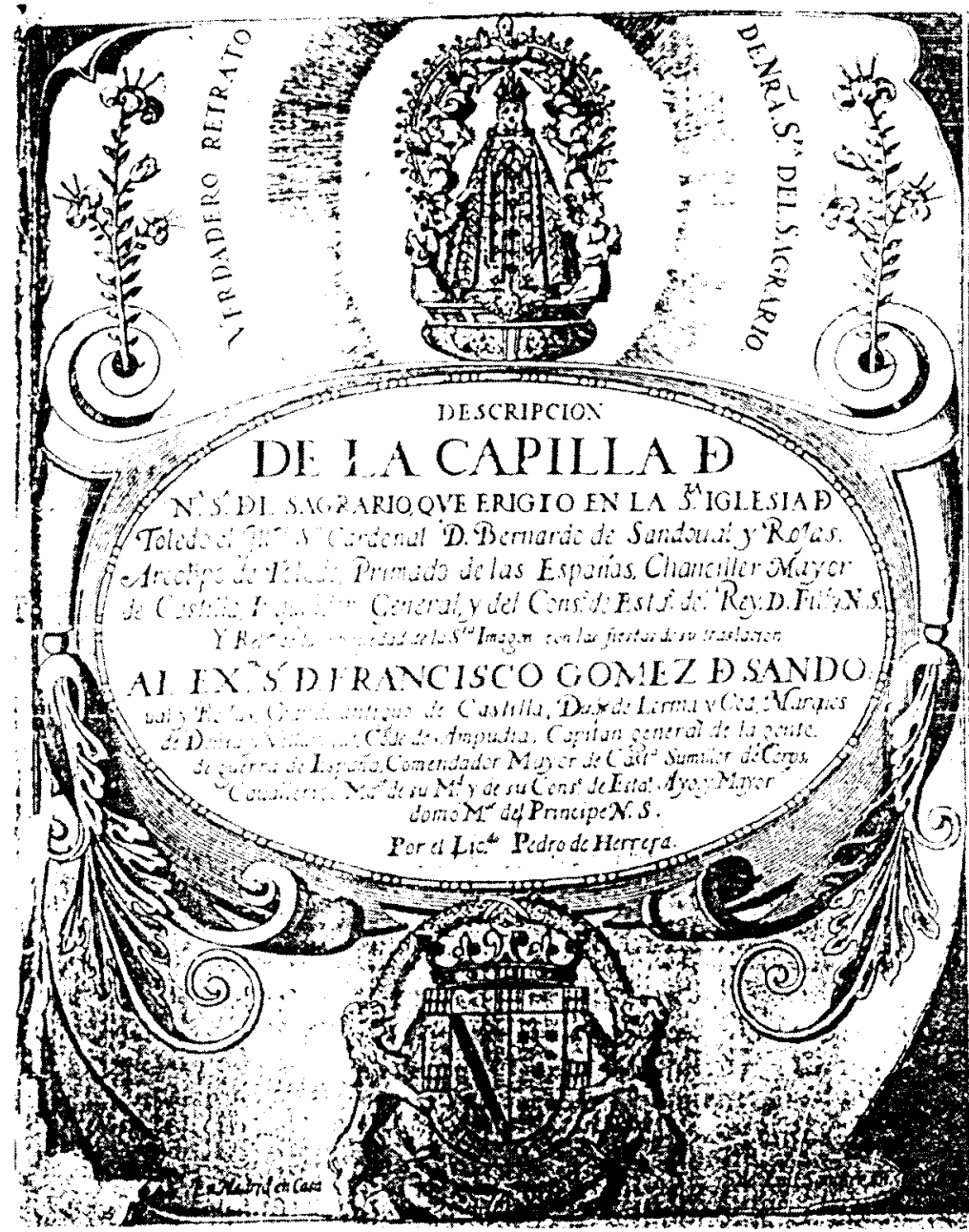

Fig. 1. Portada de la Descripción de la Capilla de Nuestra Señora dei Sagrario. por Pedro de Herrera. Biblioteca Nacional

con un Padre Eterno sobre la clave. Por el intradós se repartian seis ángeles más pequeños, como volando, con instrumentos musicales.

Los ángeles músicos son una reminiscencia de los siglos XIV y $X V$, en la que estos se reunian con diferentes instrumentos para testejar a la Virgen, especialmente en su Asunción y Coronación. En los triunfos ba. rrocos, los ángeles también acuden con sus intrumentos musicales para celebrar y solemnizar episodios importantes en la vida de los reyes y de 


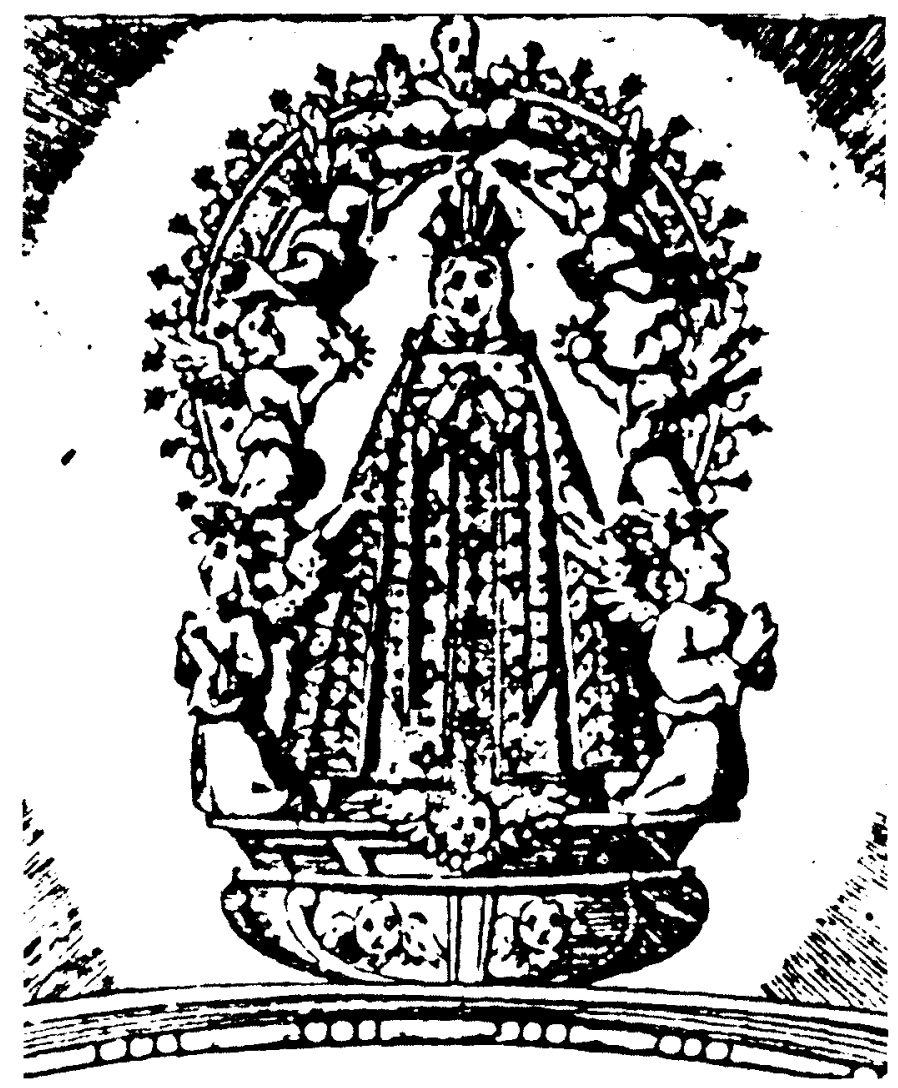

Fig. 2. Detalle de la imagen tal como se presentaba en 1616.

los príncipes. Como emisarios del Cielo, se les incluye en la escena para dar testimonio del beneplácito de Dios, del cual el rey es el representante más eminente dentro de las jerarquias humanas ${ }^{13}$.

El Cabildo decidió sustituir este primer trono durante el pontificado del arzobispo don Baltasar Moscoso y Sandoval (1646-1665). Después de construir el segundo, en el siglo XVII, quedó exclusivamente como carro procesional, pero estuvo sin utilizar durante muchos años, hasta que fue expoliado en la guerra de la Independencia, al igual que ocurrió en otras catedrales e iglesias españolas, siendo llevado a la Casa de la Moneda de Madrid, para ser fundido. 


\section{EL BALDAQUINO O GLORIA BARROCA}

Aunque la imagen de la Virgen del Sagrario es de madera, con excepción de las manos y de la cara, está revestida con una lámina de plata bastante gruesa, que la hace muy pesada, lo que dificultaba la retirada y colocación en su hornacina para los actos procesionales.

Esto, y la imposibilidad de que cupiese alli la nueva carroza o trono móvil, motivó la reforma, eliminando la reja y construyendo una nueva mesa de altar, de madera, para poder moverla con facilidad. Para ello el frente se cubria con una tela rica, cuyo color variaba, según las festividades de la Iglesia.

Sobre el altar se alzaban cuatro gradas de madera, recubiertas con plata repujada por el frente y los costados, pues no olvidemos que estamos ante el camuflaje de un carro procesional que se ve por todas partes. La imagen permanecia fija sobre el trono móvil.

Mientras estaba bajo el nicho de la capilla, el conjunto descansaba sobre unos bancos o burros con la finalidad de que los ejes de las ruedas no trabajasen constantemente soportando el peso. Estas solo apoyaban en el suelo cuando se sacaba el carro procesionalmente, saliendo de su emplazamiento mediante una rampa. Por la parte posterior se cubría con un frontal de tela rica que llegaba desde el suelo hasta el comienzo del trono.

Dos han sido los modelos que, adaptándose a los gustos artísticos de cada época, nos ha llevado al actual trono o baldaquino. Pedro de la Torre, diseñó un conjunto con una organización similar a la existente. En realidad, la modificación más aparente, será la sustitución de los ángeles orarıtes que hacián de soporte al arco de gloria, por columnas salomónicas.

El nuevo trono, seria más grande y en consonancia con el gusto barroco. Según referencias antiguas, la altura desde el arranque de la peana hasta el remate, era de unas 3 varas (unos 2,50 metrcs). Dieron trazas para construirlo en madera, varios artístas: en 1654, Pedro de la Torre; en 1655, Sebastián de Herrera y en 1656, el platero Juan de Pallares. Parece ser que también presentó el Hermano Bautista.

Las noticias sobre la elección de proyecto por el Cabildo, son dispares. Se dice que se adoptó el proyecto o modelo de Herrera "; que Herrera perdio el concurso y que lo ganó Pedro de la Torre ${ }^{15}$; se da a entender

\footnotetext{
14 Parro, Sisto Ramon. Toledo en la mano, o descripción histórico-artistica de la magnifica catedral y de los demás célebres monumentos... Tomo I. Toledo, 1857. pág. 451.

Bonet Corata, Antonio. El túmulo de Felipe iv, de Herrera Barnuevo y los retablos-baldaquinos del barroco español. Archivo Español de Arte. Números 133-136. Madrid, 1961. Tomo xxxiv. Pág. 289.
} 
que quien ganó el concurso fue Herrera, pero se volvieron a seleccionar las trazas de Pedro de la Torre ${ }^{16}$.

Creemos que de todos los proyectos presentados se eligió el de Sebastián de Herrera Barnuevo (1619-1671), arquitecto, tracista y ensamblador, discípulo de Alonso Cano, al que pagan su trabajo el 15 de febrero de 1655. Su traza se conserva en el Museo del Prado, ya que, según parece, se volvió a seleccionar la de Pedro de la Torre. Su rechazo en un primer momento, justificaría su envio a Lugo.

Otra cuestión dudosa es saber si en la traza de Pedro de la Torre, figuraban o no las columnas salomónicas. Bonet Correa sostiene que se introdujeron por encargo expreso del Cabildo, que, al contratar su realización con Fanelli exigió esta novedad que no figuraba en el proyecto, cuyo modelo de madera se conserva en la capilla de la Trinidad de la catedral de Toledo ".

Por el contrario, Virginia Tovar, dice que se incluyeron por sugerencia del cardenal comitente don Baltasar Moscoso y Sandoval, el cual manifestó el deseo de que se empleasen columnas salomónicas revestidas a oxas ${ }^{14}$. Por nuestra parte señalamos que la traza que se ejecuta en Lugo en 1655, incluía, como veremos, la nueva tipología de columna, figurando así en la traza.

Indiquemos que tanto Herrera como de la Torre, pertenecen a la escuela retablística madrileña no siendo ajenos a la influencia ejercida por Alonso Cano. Diseñan una tipología de retablo-baldaquino que va a ser utilizada por artistas, que lo difundirán por otros lugares de España. Un ejemplo puede ser el retablo del Sagrario o de los Ayala de la catedral de Segovia, de José Benito de Churriguera, que utiliza la columna salomónica rematando en semicírculo y un arco de gloria formado por ángeles, sobre el pabellón que cobija el conjunto.

El trono de la catedral de Toledo, fue construido por el escultor florentino Virgilio Fanelli, con el que firman contrato el 8 de enero de 1655. A pesar de que también le ayudaron su mujer y su hijo, el tiempo de ejecución se fue prolongando, de forma que en 1659 aun no lo habia concluido, teniendo que otorgar nueva escritura de compromiso. La obra no fue acabada hasta 1674 , después de asociarse con el platero madrileño juan Ortiz de Revilla. El primero recibió por su trabajo 400.202 reales y el segundo 171.798 .

Esta obra de orfebrería la formaban 52 arrobas de plata fina dorada y 16 arrobas, 10,5 libras de bronce para la armadura interior. El peso tota!

TOvar Martin, Virginia. Op. cit. pág. 290.

Bonet Corikea, Antonio. Op. cit. pag. 289.

Tovar Martin, Virginia. Op. cit. pág. 290. 
de la plata fue de 2.600 marcos (unos 598 kilos), y costó 577.060 reales. La mano de obra importó 572.000 reales, lo que hacía un total de 1.149. 060 reales, cifra muy importante para la época ${ }^{19}$.

En su estado actual, consta de una predela, o banco, de unos 0,80 metros de alto, y unos 3,5 metros de perímetro, con la ornamentación labrada en plata cincelada. Tiene forma de tronco de pirámide invertida, muy angulosa, articulada en forma cóncava-convexa y por consiguiente muy movida, contribuyendo a acentuar el juego de luz-sombra.

Figuras en forma de ménsula, colocadas de perfil, contribuyen a suavizar los ángulos del pedestal y su entablamento en saledizo. Esto hace que resulte más ancha la base sobre la que se apoya el arco de gloria, dando una sensación de inestabilidad característica del barroco.

En los entrepaños, formados por molduras y medias cañas, tiene medallones en altorelieve, e incluso figuras exentas, como es el caso de los ángeles de bulto redondo que, tocando instrumentos unos, y en diferentes actitudes otros, llevan atributos alusivos a la pureza y virginidad de María.

En el techo del camarin del Buen Suceso ya había serafines y ángeles revoloteando por las pilastras y arcos, claro precedente de las glorias de Lugo y Toledo. En el centro de la predela se representa un tema muy común en la iconografía barroca:

La descensión de la Virgen para imponer la casulla a San Ildefonso.

Están tambien los escudos de los prelados comitentes en el momento de iniciarse y concluirse esta gran obra de orfebreria, que eran los arzobispos don Baltasar Moscoso y Sandoval (1646-1665) y don Pascual de Aragón (1666-1677), respectivamente. También figuran los de los canónigos que eran obreros, don Pedro López de Iñarra Isasi y don Gaspar de Rivadeneira.

Sobre esta peana se asienta ia Virgen del Sagrario, cobijada bajo un arco de gioria formado por un haz de cuatro columnas a cada lado, culebrinadas o salomónicas, cuyas basas descansan sobre un alto pedestal. Sostienen un nuevo tipo de entablamento, muy movido, que llaman modiIlón y que sirve de asiento a los ángeles colocados en su arista, consiguiendo el efecto aéreo y de realismo que buscaba el barroco.

De este cornisamento arranca el arco de gloria formado por rayos, nubes, ángeles y serafines, rematando en la clave con la Santisima Trinidad, compuesta por las figuras del Padre Eterno, a la derecha, y el Verbo

Ibidem pags. $449-450$ 
Encarnado, a la izquierda. Por debajo, sobre la cabeza de la Virgen, el Espiritu Santo en forma de paloma, y encima, el globo del mundo rematado con una cruz, rodeado por una aureola de rayos y resplandores.

Este segundo trono fue modificado a finales del siglo XVIII, adaptándolo al nuevo gusto clasiscista. Las columnas salomónicas, que sostenían el arco de gloria, son sustituidas por otras de fuste estriado, de orden corintio, aprovechando el cambio para dorarlo.

\section{LA VIRGEN DE LOS OJOS GRANDES Y SU RETABLO-BALDAQUINO}

Aunque la antigua imagen de Santa Maria, conocida desde el siglo XVI como Nuestra Señora de los Ojos Grandes, era sedente, la actual, obra posiblemente del siglo XIV, es de piedra. Mide 1,75 metros de alto, por lo que su peso es considerable, debiendo de permanecer fija en su baldaquino.

Así como la primitiva respondia a la iconografía de la Virgen de la Leche, la gótica creemos que es la de la Virgen como Mater-Ecclesia. Vestida con la indumentaria romana, lleva el niño en el brazo izquierdo, mientras sostiene el pecho con la mano derecha.

Fue en el segundo tercio del siglo xvi cuando se efectuó el traslado de la imagen de la capilla mayor a una de las absidales, la primitiva de Santa Isabel y San Juan Bautista, por no permitir su peso colocarla en el nuevo retablo que construyó Cornellis de Holanda.

Parece ser que en 1655 la imagen de la patrona de Lugo, no tenía más retablo que una caja sin aspecto decente, en vista de lo cual el Cabildo decide que por cuenta de la fábrica se hiciese un retablo con la brevedad posible, previo concurso de oficiales ". Con este fin, uno de los capitulares se ofreció para escribir a un gran oficial que habia en Villafranca del Bierzo". El 13 de noviembre acordaron solicitar bula pontificia para poder pedir limosna por toda España, con destino a la capilla e imagen.

El 24 de noviembre el Cabildo establece catorce formas para conseguir dinero con destino a la obra de Nuestra Señora de ios Ojos Grandes. En el arbitrio décimo se habla de la cantidad de 800 ducados dejados por don Fernando Ares Teijeiro, arcediano de Sarria, para el culto y veneración de su

Actas capilulares del Cabido. Libro 7. Fol. 457 v. Núm. 10. AC de L.

Estos datos procedentes de las actas capitulares del Cabildo, también los recoge Lopez Marti, L.M.. El altar antiguo de Nuestra Senora de los Ojos Grandes. La Voz de la Verdad, Lugo. 15-08-1929. 
capilla, asi como otros derechos que gozaba en su nombre la fábrica, por lo que se acordó que por cuenta de la fábrica se haga un retablo ${ }^{22}$.

El 29 de diciembre del mismo año, nombran una comisión de la que formaba parte don Antonio de Neira Montenegro, arcediano de Abeancos y don Pedro Pallares y Gayoso, canónigo lectoral y secretario del Cabildo, para que en nombre de la corporación concertaran la construcción del retablo con Francisco González, maestro de obras de ensambladura y arquitecto, en la forma y manera que está la planta que se le mostró, obra por la que pide 4.050 reales $^{23}$, acordando que se hiciera la escritura y que se le anticiparan 1.000 reales.

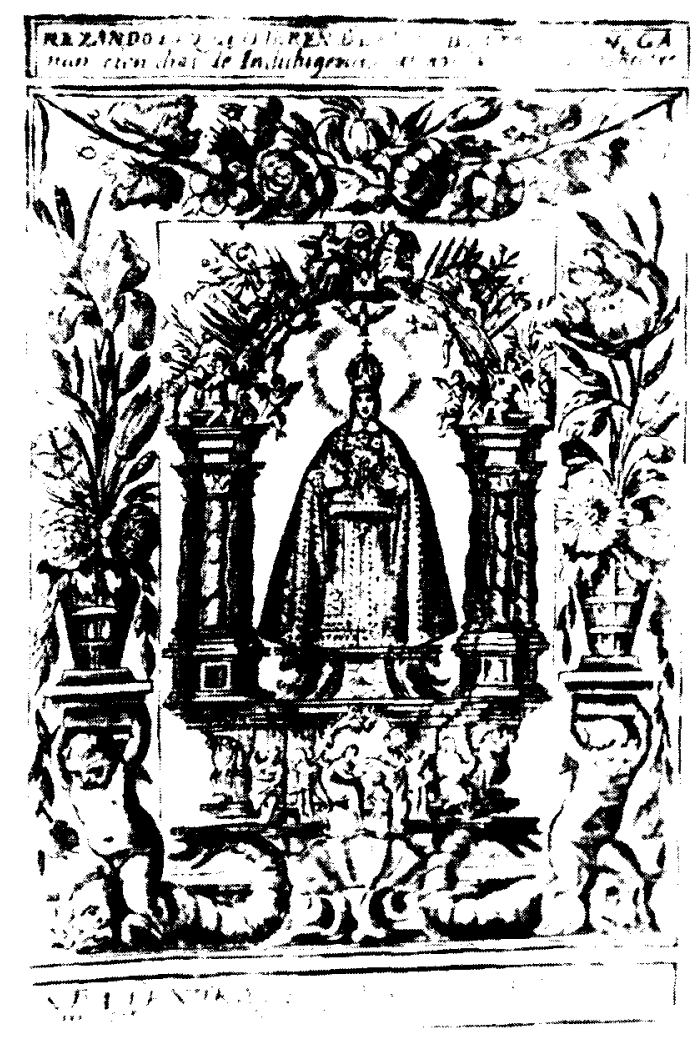

Fig. 3. Grabado de la Virgen del Sagrario de Toledo. en 1688. catorce años despues de su terminación

Libro de limosnas, legatos y transaciones ofrecidas a Nuestra Señora Santa María de Lugo de los Ojos Grandes. Fol. 38. AC de L.

Actas del Cabildo. Libro 7. Fol. 461 v. Núm. 10. AC de L. 
Al día siguiente se formaliza el contrato para hacer la obra según la traza que para ello se le dio, que es una traza que se hizo para la imagen de Nuestra Señora del Sagrario... para que según ella, y añadiendo lo más que aquí irá declarado, haga dicha obra, excepto que donde en dicha traza está la imagen de Nuestra Señora del Sagrario se halla de colocar y poner la de Nuestra Señora de los Ojos Grandes, y quedar asentada con toda seguridad, y que dicho Francisco González haya de

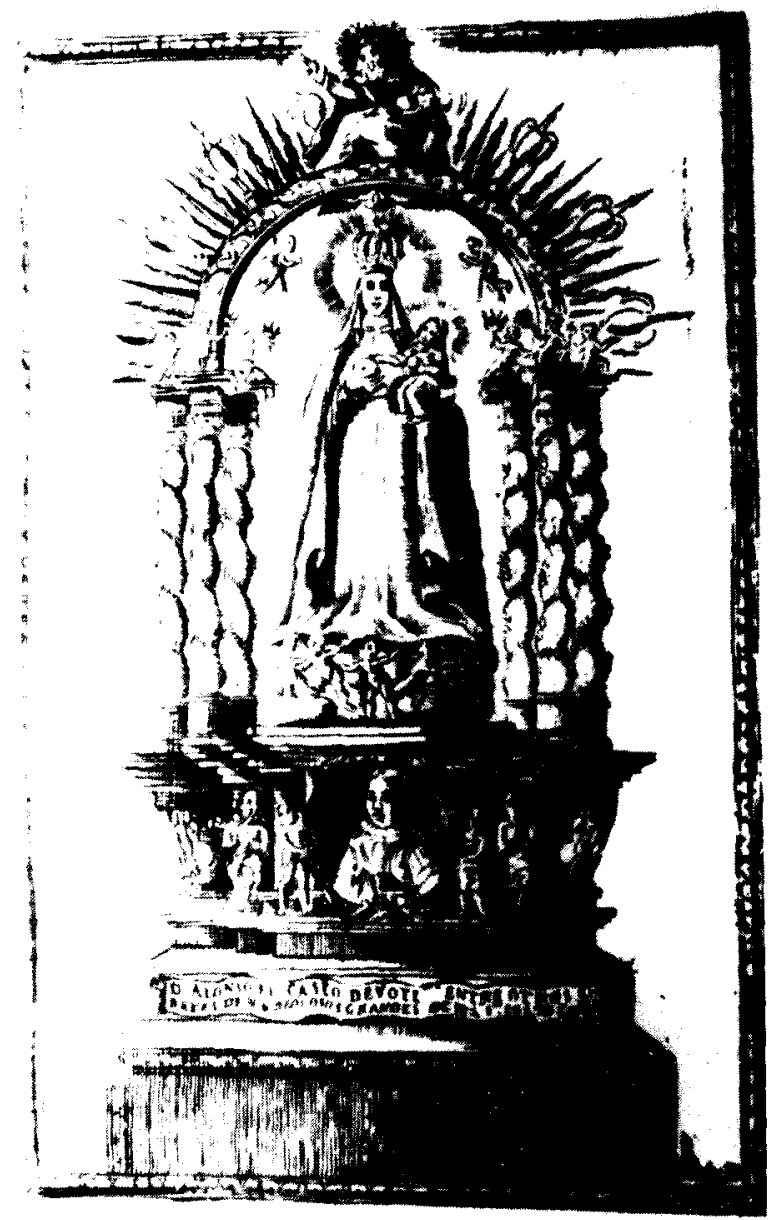

Fig. 4 Grabado de Clemente Puche, hacia 1700. La Virgen de los Ojos Grandes en ei retablo baldaquino diseñado por Pedro de la Torre en 1654. 
hacer dicha obra según dicha traza, arte y perfección de ella sin faltar cosa alguna ${ }^{24}$.

\section{UNA OBRA DE PEDRO DE LA TORRE}

Pedro de la Torre, de oficio arquitecto, ensamblador y escultor, creó un estilo propio que tuvo gran influencia a partir de la segunda mitad del siglo xvil. Aunque se sabe que es natural de Cuenca, no se conoce el lugar y fecha de nacimiento. Según Virginia Tovar ${ }^{25}$, debió nacer en los últimos años del siglo xvı, basándose en que desarrolló su actividad entre 1624 y 1677 . Hacia 1650 sería nombrado arquitecto real, pués asi consta en algunos documentos, gozando de gran prestigio, calificándole Simón López, dorador del rey, como gran ensamblador madrileño y escultor.

También son escasos los datos que se tienen sobre su formación inicial. Parece probable que tuviese la posibilidad de conocer la obra de los Mora. El estilo italianizante debió de adquirirlo en el ambiente madrileño, siendo conocedor de las obras de Serlio, Vignola y Vitrubio. Su oficio de tracista, además de los conocimientos matemáticos y del dominio del dibujo, le obligaría a la consulta de todo tipo de obra gráfica.

Si sus aportaciones a la arquitectura española de su tiempo se consideran más avanzadas que las de sus contemporáneos, siendo el que más tempranamente introdujo fórmulas italianas o europeas, su contribución al desarrollo del retablo están también en esta linea, ya que la creación del camarín, enlaza con el lenguaje expresivo del más puro barroco romano ". La utilización de la luz natural en este nuevo elemento, servirá de inspiración a los ensayos que culminarán con los transparentes del siglo XVIII.

Este aspecto novedoso, junto a la utilización por primera vez en Madrid de la columna salomónica, la potenciación de la calle central del retablo y la introducción de elementos ornamentales nuevos, supone la plena barroquización de las formas distanciándose del manierismo que imperó hasta el primer tercio del siglo XVII.

Así como no tenemos la menor duda en afirmar que el autor de la traza utilizada por el Cabildo lucense para el retablo-baldaquino de la Virgen de

\footnotetext{
Leg. 121-2. Protocolos de Diego Ares de Rois. Años 1652-55. Fol. 57. AHP de L. TOVAR Martin, ViRginia. Op. cit. págs. 261-297.

Ibidem. Pág. 268.
} 
Ios Ojos Grandes fue Pedro de la Torre, lo que no sabemos es cómo llegó a Lugo. Tenemos constatado que el contrato para la ejecución se firma el 30 de diciembre de 1655. Recordemos que en 1654 Pedro de la Torre hace una traza para el de la Virgen del Sagrario, que, según parece, fue rechazada, por la que percibe una parte de su importe y que al año siguiente hace otra Sebastián de Herrera, que es la elegida. Pero a pesar de esto, se volverá de nuevo a la primera. Advertimos también que la obra toledana en un principio sería para hacer en madera.

En la escritura de compromiso del retablo-baldaquino de la catedral de Lugo, se nos está hablando de una traza que se hizo para la imagen de Nuestra Señora del Sagrario, sin duda la desestimada en un prirner momento elaborada por Pedro de la Torre. La que se ejecutó tuvo modificaciones en la decoración de la predela. Si observamos el baldaquino actual y las descripciones que de él dan algunos autores, podemos comprobar que el motivo central de la cartela o medallón, reperesenta a la Virgen imponiendo la casulla a San IIdefonso.

Pero en el contrato para hacer el de Lugo, se aclara que en la parte y sitio que en dicha traza está puesto de medio relieve la figura y retrato del señor rey nuestro señor don Felipe quarto, que Dios guarde, se halla de poner en su lugar la figura y retrato del rey don Alonso el... (séptimo) según el traje y vestido que se usaba en aquel tiempo por haber sido ofrecido a dicha imagen de Nuestra Señora de los Ojos Grandes en su altar por la reina doña Urraca, su madre, por especial devoción a dicha imagen de Nuestra Señora ". Por tanto la traza que habia recibido el Cabildo lucense parece que tenía una representación de Felipe $V$.

La segunda cuestión es saber cómo llega a Lugo la traza.

Las tentativas para encontrar alguna referencia documental que pudiese dar luz sobre este punto, han resultado infructuosas. Nos queda movernos en el terreno de las hipótesis. Una podría ser que el Cabildo la encargase a Pedro de la Torre, cuestión que nos parece improbable, pues de lo contrario debido a su renombre, parece lógico que lo citasen.

Otra posibilidad, que nos parece más factible, es que llegase, gracias a alguna de las dignidades de la catedral de Toledo de origen gallego, vinculada por sangre o amistad con algún miembro del Cabildo. Recordemos que unos de los canónigos fabricarios en el momento de la ejecución es

Leg. 121-2. Cit. Fol. 57 v 
don Gaspar de Rivadeneira, posiblemente pariente del deán de Lugo don Juan Pardo de Rivadeneira (1642-1678).

\section{ESTUDIO COMPARATIVO}

Estamos ante una obra en la que se dan las características fundamentales del barroco:

Movilidad, juego luz-sombra, sensación de inestabilidad, y efecto aéreo.

Por otra parte, son novedades en este retablo-baldaquino, la utilización de la columna salomónica, el modillón y el camarín.

Aunque la columna salomónica no era en ese momento una novedad en Galicia, sí lo era para el resto de España. Se utiliza por primera vez en el retablo de las Reliquias de la catedral de Santiago de Compostela (1625-1630), obra de Bernardo Cabrera. La empleó por primera vez Bernini en 1624 en el baldaquino de San Pedro de Roma ${ }^{28}$.

Su origen es una columna helenística procedente de un templo dedicado al dios Baco, dividida en tres tercios: el inferior estriado, y los dos superiores con decoración de racimos de uvas y amorcillos.

La columna berninesca conserva la misma organización, pero la de Cabrera invierte la posición del decorado: las estrías pasan a ocupar los dos tercios superiores, y la figuración el tercio inferior. En el diseño de Pedro de la Torre parece que se conserva el estriado en todo el fuste y se incorporan los sármientos de la vid con los racimos de uvas.

La incorporación del modillón en el entablamento, constituye un nuevo motivo decorativo que tendrá su desarrollo y utilización en todo el barroco. Se trata de un elemento formado por la unión del mútulo o mutilo y el triglifo que adquiere un valor ornamental propio y que en los contratos denominan en ocasiones como modillón. Lo ensaya en el retablo de la Fuencisla de Segovia, pero adquiere toda su fuerza en el de Lugo y Toledo, presentándose sobre cada columna, dos de frente y otros dos de perfil, lo que da al conjunto una gran movilidad en consonancia con la predela.

La doctora Tovar considera que puede provenir del manierismo andaluz, e incluso de fuentes italianas, ya que Vignola empleó triglifos recurvados para cargar cornisas de gran vuelo y Peruzzi los utilizó en chimeneas. El

\footnotetext{
Otero Túnez, Ramon. Las primeras columnas salomónicas de España. Boletín de la Universidad Compostelana. Núm. 63. Santiago de Compostela, 1955.
} 
triglifo de gran vuelo desarrollado en el período post-herreriano, no se une al mutilo, mientras que en Pedro de la Torre forma un solo cuerpo ornamental que cabalga desde la cornisa al arquitrabe y está constituído por elementos naturalistas ${ }^{29}$.

El otro elemento es el camarín, que no estaba previsto.

En el contrato se especifica que se debia añadir a la traza pilastras a las columnas, y jambas, y tachete a forma de caja y un esplendor de serafines que tape el claro del respaldar ${ }^{30}$. Con esta incorporación se está transformando el baldaquino en un camarin. La madera sería de nogal para el retablo y de castaño para el costado. La obra tenía que estar terminada el día de Santiago, 25 de julio de 1656.

Tovar Martín, al analizar la contribución de Pedro de la Torre al retablo de su tiempo, destaca la adopción del camarín, que no se encuentra hasta ese momento en ningún lugar de España. El camarín, dice, se destaca como ejemplo luminoso al cual se subordinan los demás elementos del conjunto y en el cual se conjugan arquitectura, escultura y pintura. El propósito fundamental de esta estructura es acumular y combinar una serie de representaciones en torno a un foco principal, la imagen, que rodeada de nubes y ángeles se recorta sobre el foco de luz natural ${ }^{31}$.

Ya hablamos de las modificaciones sufridas por el baldaquino toledano. Podemos comprobar las semejanzas y diferencias con el lucense, comparando dos estampas. Una de ellas es un grabado de 1688, que representa a la imagen de Nuestra Señora dei Sagrario, según figura en el pie del mismo, como está en su trono nuevo, es decir, catorce años después de concluido, La otra es de Clemente Puche, abierta a finales del siglo XVII, para ilustrar la obra Argos Divina del canónigo Juan Pallares y Gayoso, único testimonio que nos queda del retablo antiguo de la Virgen de los Ojos Grandes de Lugo.

Organizado en dos partes, la predela o base y el cuerpo formado por un vano con arco de medio punto que forma el camarín que cobija a la imagen. El arco es un nimbo o halo flamígero, formado por una estructura semicircular de la que salen cuatro grupos de rayos, y del centro una forma semejante a la empuñadura de una espada ¿un espejo? El remate, en el baldaquino del Sagrario, se hacia con las tres personas de la Santisima Trinidad, en el de Lugo sólo aparece el Padre Eterno. El 4 de

Leg. 121-2. Cit. Fol. 57.

lbidem. pág. 279.

Actas del Cabildo. Libro 8. Fol. 118 v.AC de L. 
agosto de 1657, el Cabildo acordó que le añadiesen unos rayos y una cruz ${ }^{32}$.

El arco que forma la gloria, tiene como sustentación dos pilares fasciculados compuestos, suponemos que con cuatro columnas culebrinadas o salomónicas cada uno. Sobre el entablamento descansan ángeles que se mueven revoloteando bajo el arco.

Ya hicimos referencia al motivo central de la predela.

Tenemos que aclarar que la omisión que figura en el contrato respecto al número de orden del rey, fue debido a las dudas históricas de los miembros del Cabildo, que confundieron a Alfonso II, El Casto (791-842), con Alfonso VII, El Emperador(1105-1157), hijo de don Raimundo de Borgoña y de doña Urraca. Esta es la razón por la que el error histórico se trasladó a la estampa de Puche, en la que se puede leer:

$D$. Alonso El Casto, devoto entre otros Sres. reyes de N. S. de los Ojos Grandes desta Sta. Igl. de Lugo.

Lo correcto hubiese sido D. Alonso VII, El Emperador...

En la parte central de la predela había un medallón sostenido por dos ángeles, con el busto del rey, vestido con jubón y gorgueras, y las manos juntas haciendo oración. A ambos lados se representaban ángeles tocando trompetas.

Debido a su peso, para asegurar la imagen de piedra, se advertía en el contrato la necesidad de hacer un pilar de cantería, que correría por cuenta del Cabildo, para lo cual Francisco González tenia que facilitar la traza de como se tenía que hacer, al igual que la adpatación de la mesa del altar. Recibiría por todo 300 ducados. Hizo de fiador el licenciado don Francisco de Ron y Quirós.

Los plazos se debieron cumplir ya que el 16 de noviembre de 1656, el pintor Manuel Correa de Meneses, vecino de Villafranca, se ofrece para pintar el retablo en la cantidad de 5.500 reales, pero el Cabildo consideró excesivo el precio ${ }^{33}$. El 8 de enero de 1657, estudiaron la propuesta de Martín López, vecino de Ourense, que se comprometió a realizar el trabajo por 3. 000 reales ${ }^{34}$.

El día 14 de abril le escribieron para que viniese a cumplir lo concertado el 9 de enero, entregándole el 5 de mayo 100 ducados para traer el oro

Actas del Cabildo. Libro 8. Fol. 118 v.AC de L.

Actas del Cabildo. Libro 8. Fol. 67. AC de L.

Ibidem. Fol. $70 \mathrm{v}$ 
de Valladolid, nombrándose una comisión para que asistiese al desarme del retablo con el objeto de que no consientan se desclave cosa alguna de que se pueda ayudar ${ }^{35}$.

Parece que no tuvo ganancia en el trabajo, pues una vez terminado solicitó una ayuda al Cabildo para regresar a su ciudad.

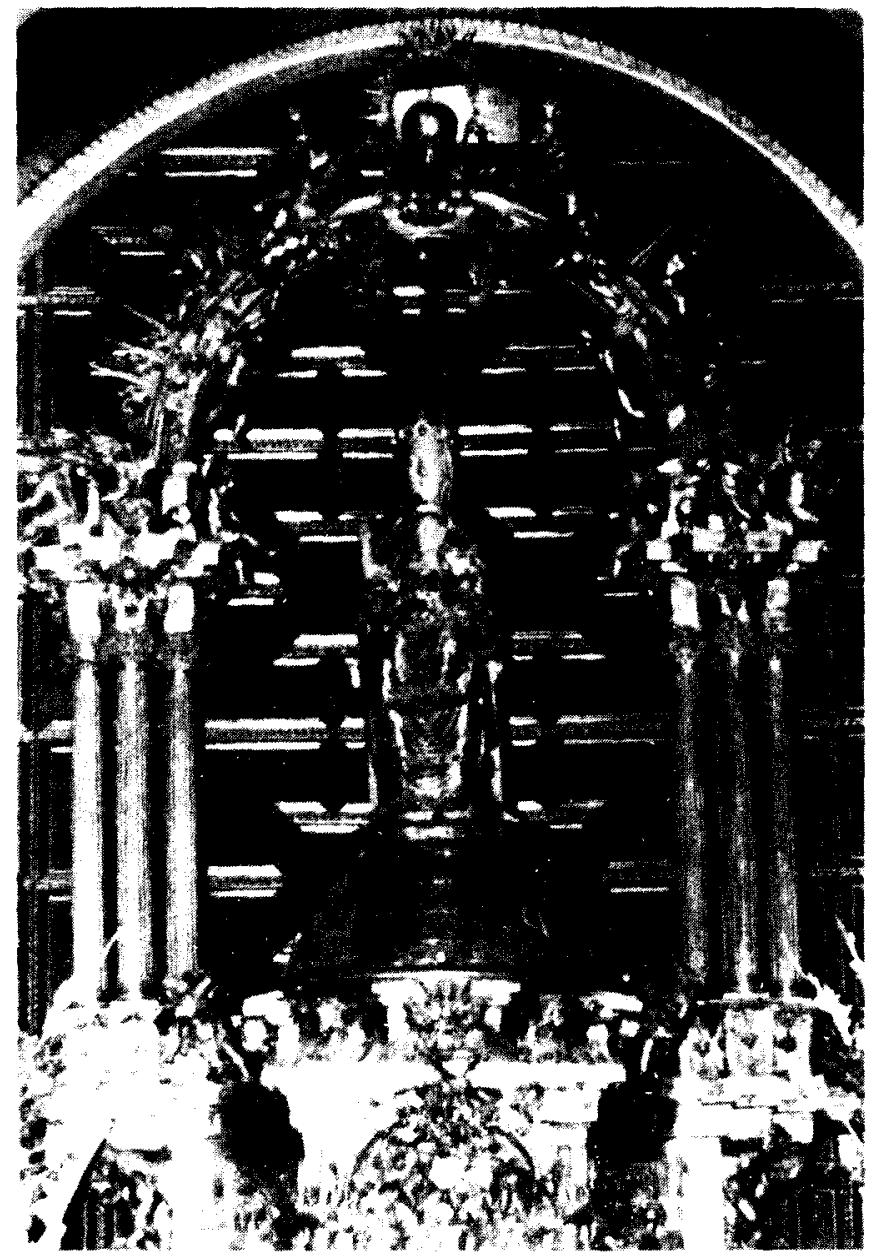

Fig. 5. La Virgen del Sagrario en la actualidad. Las columnas salomónicas del baldaquino fueron sustituidas por otras de orden corintio. 
La peana de ángeles se mantendrá en el baldaquino diseñado por el arquitecto compostelano, constructor de su capilla, Fernando de Casas y Novoa, ejecutado en 1735 por Miguel Romay.

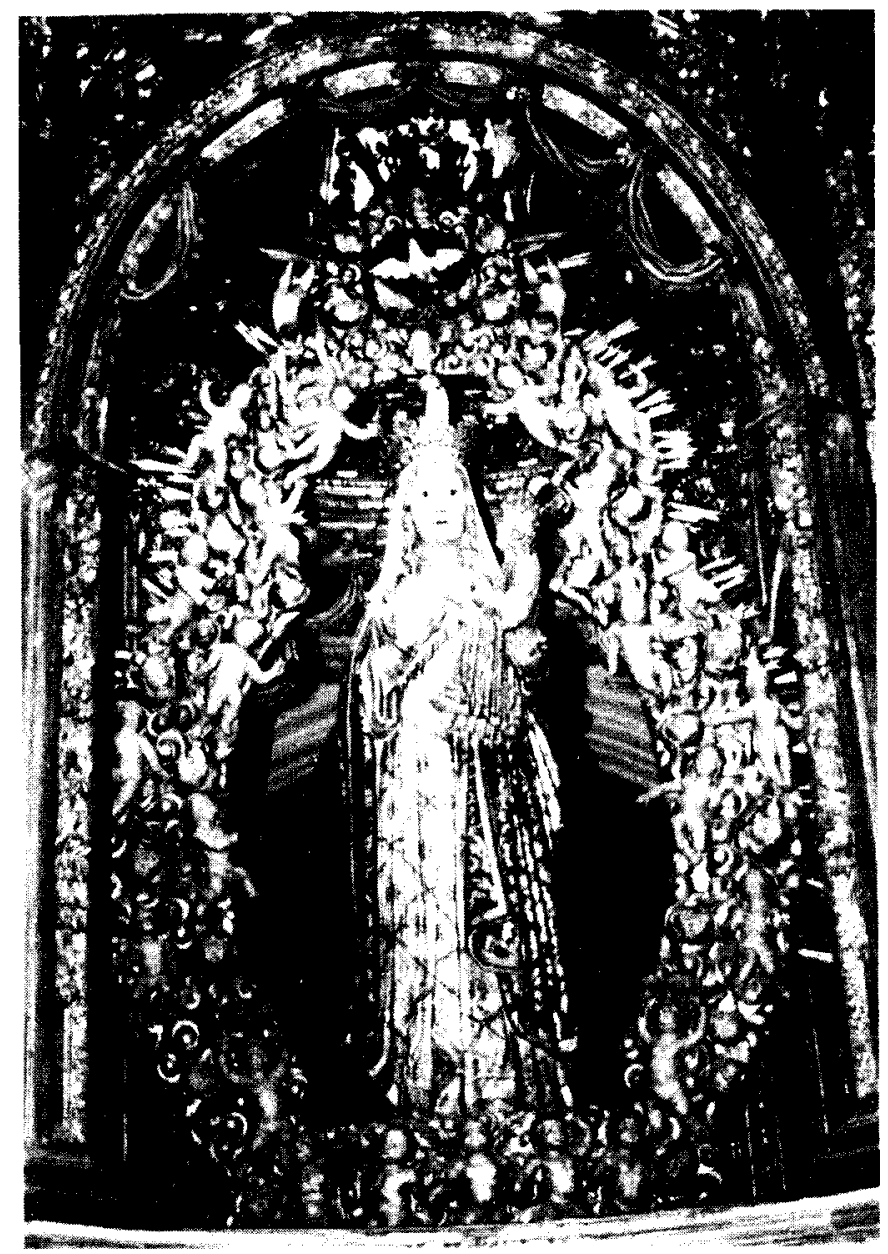

Fig. 6. La Virgen de los Ojos Grandes en su nuevo baldaquino en el que se conservó la peana de ángeles.

Conviene señalar que así como el diseño de Pedro de la Torre para la catedral de Toledo, sirvió de inspiración a Herrera Barnuevo para el de San Isidro de Madrid, y para los túmulos destinados a las honras fúnebres reales y otros monumentos conmemorativos efímeros que se van a realizar con posterioridad, la obra de Casas tiene el mismo origen. 
Creemos que este recurso, que se repetirá en la imaginería barroca, no sólo para las imagenes de la virgen sino también para representar las levitaciones de determinados santos, no es ajeno al hecho de que las dos imágenes sean las titulares y patronas de sus respectivas iglesias catedrales, celebrándose su festividad el día de la Asunción.

La incorporación de estas peanas aéreas a imágenes que por su antigüedad no responden a la citada iconografía, entendemos que lo es con el propósito de distinguir a María con el título de Reina de los Cielos. En el retablo de la iglesia del Buen Suceso de Madrid (h. 1636), coloca en el camarín, como base de la Virgen, un pequeño trono de serafines y ángeles que parecen estar en el aire. 
